\title{
Maimed Wings and Broken Hearts: Physical Disability, Social Exclusion, and Maternal Love in Disney's Maleficent and Maleficent: Mistress of Evil
}

Hannah Helm, University of Salford

\begin{abstract}
This chapter argues that Maleficent's physical difference and social exclusion can be analysed as disabling rather than villainous trajectories in Maleficent (2014) and Maleficent: Mistress of Evil (2019). I explore how Maleficent is (re)represented in the twenty-first century as a more sympathetic figure who contends with disability and social prejudice in her attempt to form meaningful connections with others. I analyse Maleficent's 'villainous' traits using Feminist Disability Studies (Garland-Thomson, 1997, 2017; Wendell, 1989) to argue that her physical and cultural differences invite hostility from the human kingdom, especially in relation to her maternal connection with Aurora. While critics have examined themes of disability and motherhood in Maleficent (Connelly, 2016; Wehler, 2019), I argue that these narratives are continued and subverted further in the sequel Maleficent: Mistress of Evil (2019). In revisioning Maleficent in this way, it becomes possible to challenge narratives of female villainy by paying attention to physical disability, social exclusion, and maternal love.
\end{abstract}

\section{Keywords}

Maleficent, Maleficent: Mistress of Evil, Disney, Gender, Villain, Disability, Motherhood, Feminist Disability Studies

\section{Biography}

Hannah Helm is a PhD student at the University of Salford. Her interdisciplinary doctoral project analyses intersectional representations of femininity, madness, and disability in nineteenth-century children's literature and Disney film adaptation. Hannah has recently published two online articles with the British Association of Victorian Studies Online and has another article forthcoming in a Special Issue of Brontë Studies in Spring 2021.

\section{Introduction}

This chapter examines how the character of Maleficent in Robert Stromberg's Maleficent (2014) and Joachim Rønning's Maleficent: Mistress of Evil (2019) (hereafter Mistress of Evil) can be reimagined as a victim, rather than a villain, through disability, social exclusion, and motherhood. Disney's live-action adaptations reinforce cultural norms associated with disability and social exclusion in order to make visible the anxieties of a normative society; yet, they also explore and bolster Maleficent's redemption through her maternal connection to Aurora. Both films create new interpretations of the 'Sleeping Beauty' fairy tale - that was first 
recorded by Giambattista Basile, Charles Perrault, and Jacob and Wilhelm Grimm - by attending to disability, social exclusion, and maternal love through Disney's creation of Maleficent. The Maleficent films therefore reimagine Maleficent's narrative purpose in contrast to the Disney animated film Sleeping Beauty (1959), where she was used to represent 'the vain, active, and wicked woman of folklore' (Bell, 1995, p. 115).

Through Geronimi's animated adaptation and the title of Rønning's live-action adaptation, the incarnation of Maleficent's character is known as 'the mistress of all evil' (Aranjuz, 2015) in popular culture, which foregrounds her reputation as a villain. However, in Maleficent and Mistress of Evil, Disney uses other aspects of the films' diegesis, such as Maleficent's physical impairment, social exclusion, and maternal love, to challenge her villainous status, newly contributing more nuanced understandings of characterisation. In doing so, both films re-evaluate Maleficent's purpose; she contends with her reputation, along with the stigma and hostility that lead to her exclusion, in an attempt to form meaningful connections with others. In this chapter, I extend feminist lines of argument and critical engagements that explore how fantastical characters are ostracised through disability (Donnelly, 2016; Resene, 2017), and I place these ideas in dialogue with Feminist Disability Studies (Garland-Thomson, 1997, 2017; Wendell, 1989) in order to interrogate how the films make visible the overlaps between gender and disability.

In this chapter, I deploy 'impairment' and 'disability' as key terms within Disability Studies that are used to understand an individual's physical or cognitive condition (impairment) and the positioning of that condition within a social environment (disability). I suggest that it is imperative to place impairment and the social construction of disability in dialogue in order to register the presence of disability within the Maleficent films. In Disability Studies, the delineation between disability and impairment has been read through the social and medical models. According to Shakespeare, 'the social model demonstrates that the problems disabled 
people face are the result of social oppression and exclusion' (2013, p. 217), whereas the medical model locates disability as a medicalised condition or 'in terms of individual deficit' (2013, p. 216). In my examination of the Maleficent films, I bring these approaches together; I argue that disability can be conceptualised through individual impairment, but it is also evidenced by social obstacles or barriers that fail to accommodate for this impairment.

By exploring connections between an individual's impairment and the social construction that culminates in disability, this chapter is attuned to the interactionist perspective that is gaining traction within Disability Studies, where the medical and social models are now being linked together. For example, Hall recognises the shortcomings of prioritising one model or key term over the other: 'the crude separation of the social (disability) from the physical (impairment) has meant that disability studies has, so far, failed to adequately theorise suffering, impairment and pain' (2016, p. 26). Through the films, I investigate how Maleficent is impaired by others, but the human kingdom of Ulstead also creates and exacerbates her disability. This ultimately demonstrates how disability 'is constructed through the relationship between an individual with an impairment and the society in which they live' (Hall, 2016, p. 168). Therefore, disability is created through individualised impairment but also social environment, and each concept can be explored in Maleficent through Maleficent's physical differences and the oppressive human kingdom.

Further, I analyse how Maleficent is positioned as the disabled 'other' through plot points and the stigmatising attitudes of human characters. I align my understanding of the 'other' with Markotić's definition, where, in the context of disability and film, the 'other' is made visible through tensions between normative and non-normative characters: 'the nondisabled remain the norm, while any and all disabilities reside in the margins' (2016, p. 175), which is further supported by Emanuel's assertion that the disabled 'comprise a group of most othered others' (2016, p. 272). This chapter responds to Siebers's claim that Disability Studies 
'does not treat disease or disability' but rather it 'studies the social meanings, symbols, and stigmas attached to disabled identity and asks how they relate to enforced systems of exclusion and oppression' $(2008$, p. 3$)$. Therefore, it is productive to interrogate how disability is constructed in a social context, and this can be seen in the Maleficent films through Maleficent's physical and cultural differences and the way that they are punished or undermined by human characters. In this context, the term 'normative' can also be understood through social understandings of disability outlined by the social model, where the ableist attitudes perpetuated by the human kingdom promote ideals or standards of behaviour, culture, and identity that exclude Maleficent.

Through this critical insight of disability, it becomes possible to identify how Maleficent's 'evil' has contributed to damaging associations that correlate disability with villainy, an association that has long been identified within children's literature and film (Crow, 1990; Markotić, 2016). In contrast to occupying a central position in the narrative, disabled characters are banished to the margins and associated with social deviance, therefore linking disability in fictional representations with evil. However, I challenge this tendency to vilify disability in order to reclaim or emancipate connections between disability and characters who occupy 'the role of a societal outcast promoted as a model of evil' (Markotić, p. 6). Disability can instead be analysed to undo or challenge Maleficent's villainous characterisation. In contrast to Maleficent's overwhelmingly negative portrayal in Sleeping Beauty, I posit that the Disney's live-action adaptations challenge the disability-as-evil trope by emphasising the social prejudice that vilifies Maleficent in the first instance, thus redeeming her for a modern audience. The Maleficent films therefore possess a critical utility in (re)telling Maleficent's story from her own perspective, and this shift in agency generates new possibilities for more nuanced understandings of female villains in fairy tale narratives. 
Although scholars are beginning to interrogate disability representations in Disney film (Norden, 2013; Smith, 2018), critical work that considers the connections between disability, gender, and representations of evil in modern fairy tale narratives is yet to be undertaken. In positioning this chapter alongside existing research on disability and villainy in live-action film adaptations (Donnelly, 2016), I extend the work of scholars who recognise the richness of Maleficent's character in Maleficent but have not yet explored the potentialities of her representation in relation to the sequel Mistress of Evil (Justice, 2014; Sharmin \& Sattar, 2018). Although current scholarship does reflect a critical interest in Maleficent's reincarnation, I propose that disability, social exclusion, and motherhood are multi-faceted experiences that work to reimagine her, and these lines of enquiry have gone largely unexamined by critics.

The aims of this chapter are threefold: first, to explore how Maleficent's physical disability in Maleficent is used to undermine her villainous status; second, to interrogate how Maleficent's purported villainy and physical difference exacerbate her exclusion from human society; and third, to analyse how Disney's live-action films challenge previous narratives of the 'Sleeping Beauty' fairy tale by emphasising Maleficent's maternal connection to Aurora. In the following sections, I therefore examine how disability and social exclusion are used to highlight Maleficent's physical and cultural differences. However, in reinforcing Maleficent's capacity for maternal love, I also suggest that Stromberg and Rønning use Maleficent and Aurora's relationship to deconstruct and reconstruct Maleficent's overall status as a victim rather than a villain.

\section{Maimed Wings and Broken Hearts: Maleficent and Physical Disability}

In Maleficent, physical disability is fundamental to Maleficent's transformation from a villain to a victim. The provision of Maleficent's backstory - a feature exempt from previous narratives of 'Sleeping Beauty' - emphasises how disability and unrequited love motivate her vengeance. As a result, Maleficent reinforces ideologies that perpetuate stigma and evil only 
to subvert them in order to bring previously unexamined perceptions of Maleficent's character into question. Both films use Maleficent's non-normativity to challenge the rhetoric of villainy that associates physical and cultural differences with evil, and these differences can be interrogated in order to examine her otherness. In his examination of disability and film, Norden argues that cinema has the potential to shape social attitudes: 'as powerful cultural tools, the movies have played a major role in perpetuating mainstream society's regard for people with disabilities' (1994, p. 1), which supports how visual modes of storytelling can influence perceptions of disabled identity. Further, Synder and Mitchell argue that '[d]isability cannot be accommodated within the ranks of the norm(als)', and as a result 'disability is either left behind or punished for its lack of conformity' (2000, p. 56). According to their central tenet of 'narrative prosthesis', disability representation is used as a metaphorical 'crutch' in texts, where disabled characters are drawn upon in order to highlight social breakdown, deviance, and marginalisation. Through a case study on Maleficent, Synder and Mitchell's argument can be perceived within a film as well as a literature context because Maleficent's disability stems from others' desire to disempower and punish her; she is maimed by a human character because she threatens the stability of their normative social order.

In Maleficent, Maleficent's disablement is made evident when Stefan, Maleficent's childhood love, maims her wings. Motivated by the promise of royal power if he kills Maleficent, Stefan's act reinscribes the norms of masculine power and able-bodied hegemony that his society represents. Maleficent, who upholds her own powerful position of Protector of the Moors (a fairy community), is left vulnerable in this moment. Stefan sedates Maleficent, and, unable to bring himself to kill her, opts to violently mutilate her instead. Discussing this scene, Leduc outlines how Maleficent's wings are '[a] prize for someone else to take' (2020, p. 167), and this act presents Stefan as the real villain because in mutilating her body he also destroys her autonomy and abilities. This scene emblematises gender inequalities because 
Maleficent is weakened by Stefan, a character who is representative of a powerful patriarchal society. However, as Leduc further states, 'the removal of Maleficent's specific mode of mobility amounts to a kind of violation with which many disabled people can identify' (2020, p. 167), which directly intersects this gendered power (im)balance with disability concerns. Further, Angelina Jolie, who performs the role of Maleficent in both films, admits that a thematic focus on female vulnerability was intentional. In discussing the scene, Jolie questions: '[w]hat could make a woman become so dark? To lose all sense of her maternity, her womanhood, and her softness?' (2014). In this moment, the viewer witnesses the pivotal event that motivates Maleficent's vengeance. Nevertheless, despite experiencing extreme violence, Maleficent does not 'lose all sense of her maternity' because her love for Aurora is a catalyst that later works to mend her broken heart.

The cinematographic and aesthetic choices of this scene intensify Maleficent's suffering; a grey, sombre lighting is used to heighten the moment where Maleficent awakens and realises that Stefan has mutilated her. The significance of colour within film is supported by Schögl and Zagalo's claim that 'colour is an integral part of audio-visual language and is extremely important for the construction of messages' (2019, p. 164). The colour grey is used here to highlight a sense of bleakness and loss in relation to Maleficent's maimed body. Maleficent's distress is expressed through screaming, while a combination of camera shots is used to illustrate an important contrast: the camera zooms in on the vulnerable Maleficent, but it also captures a distant shot of the castle to link Maleficent's suffering directly with the human kingdom. The work of Garland-Thomson can be used to interpret Maleficent's oppression here since she claims that ' $[w]$ omen and the disabled are portrayed as helpless, dependent, weak, vulnerable, and incompetent bodies' (2017, p. 365). In this scene, Stefan's actions render Maleficent 'helpless', 'weak', and 'vulnerable', and so gender and disability concerns intersect at the site of Maleficent's body in order to heighten her subjugation. Consequently, Stefan's 
act emblematises how the normative, able-bodied male character triumphs over the disabled female character, and Maleficent is disempowered through her gender and disability. This leads her to befriend a raven named Diaval so that he can perform the role that she no longer can, which is communicated in the line: 'I need you to be my wings' (Stromberg). Although Maleficent does regain her wings at the end of Maleficent, her reliance on Diaval throughout the film's diegesis is used to fulfil her own inability to witness events because, without her wings, she is rendered incapable and helpless. Disability therefore becomes a reminder of Maleficent's oppression as a fairy at the hands of the human kingdom, and as a result she is portrayed as a victim rather than a villain.

\section{'I spread the story of the evil witch, and the princess she cursed [...] They were all terrified, and the story became legend': Maleficent and Social Exclusion}

Maleficent is a victim of social exclusion in both films, and this adds impetus to the ways in which physical difference heightens her 'otherness' from human society. In Theorising Social Exclusion, Taket et al. explore how concepts of 'social exclusion' are contested and hold meaning in a variety of cultural, political, and economic contexts. Yet, in its original definition of exclusion sociale, the term is used to signify 'a rupture of social bonds' and 'the idea of deviance or non-conformity' (2009, p. 8). These definitions can be traced through Maleficent's character; her differences mean that she cannot align to the values of the human kingdom. In Maleficent and Mistress of Evil, Maleficent's 'social bonds' with human characters such as Stefan and Aurora are ruptured or tested by societal pressures that seek to exclude her. This suggests that the normative social order constructs a sense of 'normalcy' that accounts for her marginalisation. In both films, human characters adopt a stigmatising attitude in order to 'other' Maleficent and the fairy kingdom. This idea can be contextualised using the work of Davis, a disability scholar who coined the term 'normalcy' to argue that disability in literature is used to reinforce the ubiquity of the 'normal' within society. Although his germinal work examines 
how literature semiologically promotes normalcy by paying attention to disability, I suggest that Davis's argument, where he claims that 'the "problem" is not the person with disabilities; the problem is the way that normalcy is constructed to create the "problem" or disabled person' (1995, p. 24), can be extended through film. In presenting Maleficent as a non-normative 'other', Disney is attuned to the 'pity, discomfort, disdain' that are 'overwhelmingly presented as normative societal responses to the disabled' (Donnelly, 2016, para. 24). However, both films also provide a tantalising glimpse into Maleficent's humanity and vulnerability in order to reimagine her as a victim rather than a villain; on a paradoxical level, the plots of each film exclude Maleficent in her own social context in order to include or redeem her within the cultural imagination. The diegesis of both films therefore draws on dominant narratives that perpetuate 'normalcy' in order to expose the normative power dynamics that construe villainy. The following statement by Davis is useful for my purposes here:

[T]here is an assumption that society at large is intact, normal, setting a norm, undamaged. But the notion of an undamaged observer who is part of an undamaged society is certainly one that needs to be questioned. (1995, p. 14)

Here, Davis shifts the focus of enquiry from the non-normative individual to normative society as a whole, and this shift is crucial for reimagining Maleficent's villainous status. Maleficent and Mistress of Evil modify Maleficent's character in order to call attention to societal prejudices. In conceptualising how normalcy juxtaposes disability in order to reaffirm dominant cultures of normativity, it becomes possible to explore how Maleficent is targeted by a human kingdom that emblematises normalcy through two scenes: Maleficent's deliberate exclusion from Aurora's christening, an important social event (Maleficent) and Maleficent's refuge in an underground community (Mistress of Evil), where she resides with other fairies in order to escape human oppression.

In Maleficent, Maleficent's social exclusion is made explicit through Aurora's christening. The human kingdom gathers to celebrate the newborn child of Stefan, who, 
following the attack on Maleficent, is now King. Prior to Maleficent's arrival, three fairies, Knotgrass, Thistlewhit, and Flittle, bestow magical gifts upon Aurora. The connotations of their names, such as the phonetic similarities between 'flittle' and 'fickle', indicate their incompetence as Aurora's godmothers, thus paving the way for Maleficent's maternal love later on. The mise-en-scène of Maleficent's arrival starkly contrasts with the colourful celebrations taking place beforehand; candles are blown out, the scene darkens, and dramatic music represents the fear of the townspeople. Further, Maleficent's shadow is seen before she is, which heightens her position within the human kingdom as an ambiguous, terrifying enigma, whose reputation haunts the kingdom. During a confrontation with Stefan, Maleficent makes her exclusion clear in the line: 'I really felt quite distressed at not receiving an invitation', while Stefan explains that she is 'not welcome here' (Stromberg) in an exchange that encapsulates her outsider status. In bestowing her own gift on Aurora, Maleficent uses the opportunity to regain the power that Stefan took from her when he maimed her wings; she makes him beg for mercy: 'I like you begging. Do it again' (Stromberg). Through her command, Maleficent emasculates Stefan, and it is poetic justice that Maleficent bestows a sleep curse on Aurora where only true love's kiss can break the spell - in order to undermine her lost love with Stefan but also compensate for her own enforced sedation earlier on.

Maleficent's social exclusion is reinforced in Mistress of Evil; however, this exclusion goes beyond Maleficent as an individual character and extends to the entire fairy kingdom. Maleficent flees Ulstead after a confrontation with Philip's mother, Queen Ingrith, and Gerda - Ingrith's trusted assistant - shoots Maleficent with an iron bullet. Iron is poisonous for fairies, and Maleficent is rescued by Conall, a fairy of her own kind. Conall takes Maleficent to an underground cave where other fairies are hiding from the humans. Unlike Maleficent's exclusion from the christening in Maleficent, the hostility between the human and fairy kingdoms is amplified in Mistress of Evil. Unable to return to the Moors after her attack, 
Maleficent remains underground. In her feminist approach to disability, Wendell outlines the multi-faceted oppression that underpins female experiences:

[W]omen (and children) have been relegated to the private, and so have the disabled [...] The public world is the world of strength, the positive (valued) body [...] Weakness, illness, rest and recovery, pain, death and the negative (de-valued) body are private, generally hidden [...] Much of our experience goes underground, because there is no socially acceptable way of expressing it. (1989, p. 111)

Here, Wendell establishes a dichotomy between 'valued' and 'de-valued' bodies, and the terms 'private', 'hidden', and 'underground' suggest negative connotations that can be understood as antithetical to able-bodied normativity. Although Wendell contextualises her discussion using the lived experiences of real women, her metaphor has a critical application to this scene in Mistress of Evil. In a paralleled fashion, irreconcilable differences between the human and fairy kingdoms are seen through the dichotomous public and private realms, which in turn encapsulates the physical and cultural differences that exist between Ulstead and the Moors. In a similar thread to her maiming in Maleficent, the human kingdom is presented as villainous while Maleficent is victimised. Yet, the human world dominates through its own normativity while Maleficent is literally and figuratively 'othered'. The two scenes are mirrored, and closeup shots of Maleficent's wings in each scene recapitulate the connections between her physical difference and her mistreatment by the humans. Following her awakening, Maleficent travels through an underground tunnel to meet the fairies in the cave, which bears further similarities to Wendell's metaphor; in both contexts of Wendell's argument and Maleficent's characterisation, multi-faceted identities of gender and physical difference are compounded in order to highlight individual oppression.

In her venture through the cave, Maleficent encounters a more colourful underground space, where the fairies and their families live peacefully despite the hostility between the Moors and Ulstead. Here, the more sombre aspects of Maleficent's character, that can be understood through Wendell's metaphor, are counteracted by an emancipating, alternative 
space that exists beyond the human kingdom. Through Conall, Maleficent learns about the origin of this underworld:

Conall: As more human kingdoms emerged, we went into hiding from every corner of the earth, doing what we had to do to survive.

[Maleficent remains silent.]

Conall: Our only refuge is here. In this cave. Our nest of origin. (Rønning)

As Conall and Maleficent fly through the cave, Conall details the history of the fairy refuge. Despite the darker, hidden parameters of the cave, its natural qualities, seen through an abundance of trees, jungles, and plants, emphasise how the cave also functions as an organic, generative realm where fairies can thrive away from human oppression. In contrast to the more intrusive camera shots used during Maleficent's maiming and her awakening after Ingrith's attack, camera shots in this scene encompass Maleficent, the fairy community, and the environment in a single frame. This visual manifestation of unity and liberation was previously exempt during Maleficent's individual moments of pain, humiliation, and isolation earlier on. Nevertheless, although Conall is optimistic about a future reconciliation between Ulstead and the Moors, Maleficent is defiant that 'it will never happen' (Rønning), thus encapsulating the human prejudice that sustains the fairy community as perpetual and undesirable 'others'.

\section{'I know who you are. You're my mother': Maleficent and Maternal Love}

It is only through engaging with Maleficent's disability and social exclusion can the films begin to revision her character by exploring her maternal love for Aurora. This departs from other fairy tale narratives of 'Sleeping Beauty' because Aurora and Maleficent are presented as family rather than foils. By exploring Maleficent's maternal connection to Aurora, Stromberg and Rønning suggest that alternative forms of motherly love, such as adoptive motherhood rather than biological or step-motherhood (where the latter is a common trope of female villainy in other fairy tale narratives such as 'Snow White' and 'Cinderella'), are powerful enough to override the hostility displayed by other human characters. As such, Maleficent and 
Aurora's relationship redeems Maleficent by highlighting her more benevolent, humane qualities while also demonstrating an allegorical reunion between Ulstead and the Moors; the two kingdoms become linked through their connection.

In Maleficent, Disney subverts the trope of 'true love's kiss' in order to rework archetypal fairy tale narratives that depend on this device. Although this subversion can be read as a feminist modification of the traditional fairy tale because the film undermines patriarchal ideologies of heroic men and weak women (Shapiro, 2014; Wehler, 2019), the trope is used instead to highlight Maleficent's capacity for maternal love. The trope of 'true love's kiss' is conventionally employed, especially in twentieth-century Disney animated adaptations, to 'emphasise true love, with love-at-first-sight the preferred type' (Wood, 2015, p. 157) between two heterosexual characters. Through the live-action films, Disney removes the romantic emphasis that shaped previous narratives by exploring how Aurora can only be revived from her curse through Maleficent's maternal kiss, thus nurturing a familial relationship between Aurora and Maleficent in contrast to Aurora and Philip's romantic love. In order to highlight Maleficent and Aurora's connection, the film draws on the concept of 'looking'. In the scene where Philip fails to revive the sleeping Aurora, the viewer witnesses how Aurora and Philip are bathed in natural sunlight while Maleficent lurks in the shadows. Maleficent gazes on the scene through a translucent barrier, where she can glimpse at but not clearly see the unfolding event. This highlights how Maleficent cannot yet metaphorically 'see' that she is Aurora's true mother and that only her love - not Philip's - is powerful enough to destroy the curse. After Phillip leaves, Maleficent enters the room and is inflected with a different kind of natural light: fire. Here, fire recapitulates Maleficent's purported villainous status, where the element is traditionally connotated with danger or pain. However, the film proceeds to undercut this association by emphasising Maleficent's remorse rather than vengeance:

Maleficent: I was so lost in a hatred and revenge [...] you stole what was left of my heart, and now I've lost you forever. 


\section{[Maleficent cries.]}

Maleficent: I swear, no harm will come to you as long as I live, and not a day shall pass that I don't miss your smile. (Stromberg)

[Maleficent kisses Aurora on the forehead.]

Maleficent's nurturing, protective approach towards Aurora highlights her vulnerability in contrast to her previous coldness. Maleficent originally punished Aurora because she reminded her of her own failed love with Stefan, but ironically the foundations of Maleficent's love can now only be fulfilled by Aurora herself. This is supported by Schögl and Zagalo's claim that, throughout the film, Maleficent's 'facial expression and posture, along with her tone of voice, are imperative to identifying her function' (2019, p. 164). Through her body language and emotion in this scene, Maleficent's maternal 'function' is made clear. Maleficent holds Aurora's hand while Diaval narrates their 'true love' (Stromberg) as mother and daughter, which challenges Maleficent's villainy by emphasising the rawness of her maternal love. The scene concludes with a zoomed out shot of Maleficent and Aurora in a mother-daughter embrace, and this illuminates not only their familial connection but also a unity between the fairy and the human, or, the normative social order and the non-normative 'other'. As Donnelly outlines, their relationship is integral to a reconciliation between the two communities and an ability to 'credibly challenge the villainous label that has been ascribed to Maleficent' (2016, para. 25). Such a reading therefore makes visible how Aurora is used to validate Maleficent's capacity for maternal love in order to redeem her from villainy.

Maleficent and Aurora's maternal dynamic is explored further in Mistress of Evil, where Ingrith presents a challenge to Maleficent's newly established maternal role, and her stigmatising attitudes attempt to resituate Maleficent as the 'other'. Ingrith draws on Maleficent's unfavourable reputation in order to invalidate her bond with Aurora because she epitomises the normative social order that Maleficent is both excluded from and targeted by. In this thread, Maleficent is victimised by a culture that values motherhood as a duty reserved for humans rather than fairies, and, in criticising Maleficent's physical and cultural differences, 
Ingrith is able to adopt the position of 'normate'. 'Normate' is a term first defined by GarlandThomson, and it 'designates the social figure through which people can represent themselves as definitive human beings'. Those who occupy the normate 'step into a position of authority and wield the power it grants them' (1997, p. 8). Garland-Thomson's definition, that operates within an overarching context of disability and social exclusion, can be seen here because Ingrith draws on this identity position to reaffirm her own normativity. By extension, she is able to alienate Maleficent because she represents everything that Ingrith is not. This concept is made explicit in the following example, where Ingrith undermines Maleficent's maternal capabilities during a celebration for Aurora and Philip's engagement:

Ingrith: You have done an admirable job, Maleficent, going against your own nature to raise this child. But now Aurora will finally get the love of a real family. A real mother. (Rønning)

Ingrith's preoccupation with 'real' motherhood and its interconnectedness to human, rather than fairy, 'nature' encapsulates the purported incompatibilities between Maleficent and motherhood that link back to differences between Ulstead and the Moors. The cultural construction of motherhood as a privilege or duty reserved for normative, able-bodied individuals can be contextualised using Tarasoff's work on able-bodied and disabled motherhood. Tarasoff outlines how physical differences are perceived as incompatible with norms of motherhood, even in the twenty-first century: 'people with disabilities are considered to be inherently defective and "unruly", [however] there is value in the "unruly" disabled body and $[\ldots]$ there is much to learn from the experiences of often marginalized bodies' (2020, para. 4). Tarasoff's ability to reclaim or validate motherhood - that can be experienced by many, not only the able-bodied - is reminiscent of Maleficent's ability to 'mother' Aurora despite Ingrith's prejudices.

In another example later on, Maleficent, Ingrith, and Aurora have a final confrontation during the inevitable war between Ulstead and the Moors. In this scene, the setting once again 
recapitulates the event; the confrontation takes place on a crumbling tower attached to Ingrith's castle, smoke fills the atmosphere, and a variety of camera shots are employed to capture themes of disorientation and dysfunction. These creative choices symbolise how the structures of Ingrith's universe - the ones she uses to validate her own normative position in order to invalidate Maleficent's - literally and metaphorically break down when Aurora and Maleficent reunite. In a final attempt to vilify Maleficent, Ingrith once again draws on her reputation and physical difference:

Ingrith: There's the evil that I promised them.

[Maleficent crouches before standing and turning towards Ingrith.]

Ingrith: Your kind is more predictable than humans. (Rønning)

[Maleficent walks towards Ingrith.]

Here, Maleficent is presented as physically small and vulnerable through her body language, but she is able to regain her power. Motivated by Ingrid's hatred and a desire to protect Aurora, Maleficent's movements rebalance their power dynamic; she does not allow Ingrith to destroy her, and, by association, her maternal body or the object of her maternal love (Aurora). Unaffected by Ingrith's prejudice, Aurora confirms Maleficent's maternal purpose in order to counteract the normative social order that seeks to vilify her:

Aurora: I know who you are. I know you.

Maleficent: You do not!

Aurora: Yes I do. You're my mother! (Rønning)

In contrast to Maleficent's affection towards Aurora in Maleficent, where she uses maternal love to lift Aurora's curse, the opposite is apparent here: Aurora reaffirms their relationship in order to save Maleficent from the humans. Maleficent's maternal bond with Aurora is once again able to defy the social prejudices that the human kingdom represents, and this highlights the generative potential of non-normative motherhood in twenty-first century fairy tale narratives. In exploring their mother-daughter dynamic across both films, Disney emphasises how humanity, compassion, and love - not evil - are the fulcrum of Maleficent's overall construction. 


\section{Conclusion}

By exploring Maleficent's disability, social exclusion, and maternal love in Maleficent and Mistress of Evil, her character can be reimagined as a misunderstood victim rather than a quintessential villain. The ability to revision Maleficent, a character who is culturally laden with wickedness and vengeance, gives shape and meaning to broader understandings of female villains in fairy tale narratives. As the first Disney 'villain' to receive their own eponymous franchise, alternative narratives surrounding Maleficent's character suggest that Disney is becoming more attuned to the possibilities of rewriting fairy tale villains in the twenty-first century. Through these films, Disney exploits the potential that live-action mediums of storytelling offer for more nuanced interpretations of characterisation and identity by making visible the intersections between gender, disability, and motherhood. Therefore, the Maleficent films represent the continued relevance of Maleficent as a canonical fairy tale villain who, through Disney's reimagining, can be (re)represented as a more sympathetic figure who contends with disability and social exclusion in her attempt to form maternal connections and friendships. 


\section{References}

Aranjuz, A. (2015). A different shade of evil: Question of ethics in Maleficent. Screen Education, 76(1), 8-16.

Bell, E. (1995). Somatexts at the Disney shop: Constructing the pentimentos of women's animated bodies. In: Bell. E, Haas. L \& Sells. L (Eds.), From mouse to mermaid: The politics of film, gender, and culture. (pp. 107-124). Indiana: Indiana University Press.

Crow, L. (1990). Disability in children's literature. Retrieved January 26, 2021, from http://www.roaring-girl.com/wp-content/uploads/1990/07/Representation-in-ChildrensLiterature.pdf

Davis, L. (1995). Enforcing normalcy: disability, deafness, and the body. London: Verso.

Donnelly, C. (2016). Revisioning archetypes of disability and deformity in fantasy: Wicked, Maleficent, and Game of Thrones. Disability Studies Quarterly, 36(4). http://dx.doi.org/10.18061/dsq.v36i4.5313

Emanuel, C. (2016). The disabled: The most othered others. In: Goodman, D. \& Severson, E. (Eds.), The ethical turn: otherness and subjectivity. (pp. 270-286). Oxon: Routledge.

Garland-Thomson, R. (1997). Extraordinary bodies: Figuring physical disability in American culture and literature. New York: Columbia University Press.

Garland-Thomson, R. (2017). Integrating disability, transforming feminist theory. In: Davis, L. (Ed.), The disability studies reader. (5 ${ }^{\text {th }}$ ed., pp. 360-381). Oxon: Routledge.

Hall, A. (2016). Literature and disability. Oxon: Routledge.

Jolie, A. (2014). Woman's Hour. Retrieved February 26, 2021, from https://www.bbc.co.uk/programmes/b0460hz8

Justice, B. (2014). Maleficent reborn: Disney's fairytale view of gender reaches puberty. Social Education, 78(4), 194-198.

Leduc, A. (2020). Disfigured: On fairy tales, disability, and making space. Toronto: Coach House Books.

Markotić, N. (2016). Disability in film and literature. North Carolina: McFarland.

Mitchell, D., \& Snyder, S. (2000). Narrative prosthesis: Disability and the dependencies of discourse. Michigan: The University of Michigan.

Norden, M. (1994). The cinema of isolation: A history of physical disability in the movies. New Jersey: Rutgers University Press.

Norden, M. (2013). "You're a surprise from every angle": Disability, identity, and otherness in The Hunchback of Notre Dame. In: Cheu, J. (Ed.), Diversity in Disney films: Critical essays on race, ethnicity, gender, sexuality, and disability. (pp. 163-179). London: McFarland. 
Resene, M. (2017). From evil queen to disabled teen: Frozen introduces Disney's first disabled princess. Disability Studies Quarterly, 37(2). http://dx.doi.org/10.18061/dsq.v37i2.5310

Rønning, J. (2019). Maleficent: Mistress of Evil. Walt Disney Pictures.

Schögl, L. \& Zagalo, N. (2019). From animation to live-action: reconstructing Maleficent. In: Barker, A. \& Callahan, D. (Eds.), Body and text: cultural transformations in new media environments. (pp.157-171). New York: Springer.

Shakespeare, T. (2013). The social model of disability. In: Davis, L. (Ed.), The disability studies reader. ( $4^{\text {th }}$ ed., pp. 214-221). Oxon: Routledge.

Shapiro, J. (2014). Why Disney's Maleficent matters. Retrieved February 5, 2021, from https://www.forbes.com/sites/jordanshapiro/2014/06/05/why-disneys-maleficentmatters/?sh=32fd0bcf3901

Sharmin, T. \& Sattar, S. (2018). Gender politics in the projection of Disney villains. Journal of Literature and Art Studies, 8(1), 53-57.

Siebers, T. (2008). Disability theory. Michigan: The University of Michigan.

Smith, K. (2018). It's a pity and a sin: Images of disability, trauma and subverted power in Disney's Beauty and the Beast. Word and Text, 18(1), 111-128.

Stromberg, R. (2014). Maleficent. Walt Disney Pictures.

Taket, A., Crisp, B., Nevill, A., Lamaro, G., Graham, M., \& Barter-Godfrey, S. (2009). Theorising social exclusion. Oxon: Routledge.

Tarasoff, L. (2020). A call to recognise the value in disability. CMAJ, 191(16). https://doi.org/10.1503/cmaj.71763

Wehler, M. (2019). “Hello, beasty": Uncompromising motherhood in Disney’s Maleficent. In: Frankel, V. E. (Ed.), Fourth wave feminism in science fiction and fantasy. (pp. 102-115). North Carolina: McFarland.

Wendell, S. (1989). Toward a feminist theory of disability. Hypatia, 4(2), 104-124.

Wood, N. (2015). Walt Disney. In: Zipes, J. (Ed.), The Oxford companion to fairy tales. (pp. 154-159). Oxford: Oxford University Press. 